\title{
Maternal Obesity and Its Associated Factors and Outcomes in Klang Valley, Malaysia: Findings from National Obstetric Registry
}

Nurul Farehah Shahrir, Rohana Abdul Jalil, J Ravichandran R Jeganathan, Shamala Devi Karalasingam, Noraihan Mohd Nordin, Mohamad Farouk Abdullah, Nadiah Sa'at

S Nurul-Farehah, AJ Rohana, J Ravichandran, et al. Maternal Obesity and Its Associated Factors and Outcomes in Klang Valley, Malaysia: Findings from National Obstetric Registry. Malays Fam Physician. 2021;16(3);56-67. https://doi.org/10.51866/oa1138

Keywords:

Maternal obesity, national

obstetric registry, associated

factors, ethnicity.

\section{Authors:}

Rohana Abdul Jalil

(Corresponding author)

MSc, Ph.D (Community Nutrition)

(USM)

Department of Community Medicine

Universiti Sains Malaysia, Health

Campus, Kubang Kerian, Kelantan Malaysia

Email: rohanajali|@usm.my

Nurul Farehah Shahrir

Candidate Doctor of Public Health MBBS (UiTM), MPH (USM)

Department of Community Medicine Universiti Sains Malaysia, Health

Campus, Kubang Kerian, Kelantan Malaysia

\section{J. Ravichandran $\mathbf{R}$ Jeganathan MD (USM), MMed Obstetrics and Gynecology (USM) \\ Department of Obstetrics \& \\ Gynaecology, Hospital Sultanah Aminah, Johor Bahru, Ministry of Health, Malaysia}

\section{Shamala Devi Karalasingam} MD(Mangalore University), MMed Obstetrics and Gynaecology (University Malaya) National Obstetrics Registry, Institute Clinical Research,National Institute of Health, Ministry of Health, Malaysia

\section{Abstract}

Introduction: Maternal obesity presents significant health risks to mothers and their fetuses. This study aimed to determine the proportion, associated factors and outcomes of maternal obesity among pregnant women in Klang Valley, Malaysia.

Methods: A retrospective cross-sectional study was conducted between January 2018 and March 2018 using secondary data from the Malaysian National Obstetric Registry (NOR) for the year 2015. All pregnant women with first-trimester booking at 12 weeks and below that were registered with the NOR and met the inclusion and exclusion criteria were included in the study. Descriptive statistics and multiple logistic regression analysis were used. Data were analysed using SPSS version 22.0. A total of 2113 respondents were included in this study to determine the proportion, associated factors and outcomes of maternal obesity. Regarding the univariate and multivariate analyses, respondents were classified into two groups: normal and obese. The obese group comprised overweight and obese mothers. The underweight group was excluded in the subsequent analysis.

Results: Out of the 2113 respondents, $7.1 \%$ were underweight, $41.7 \%$ were of normal weight, $28.6 \%$ were overweight, $15.9 \%$ were in obese class I, $4.6 \%$ were in obese class II, and $2.1 \%$ were in obese class III according to the WHO (1995) reference. However, when the MOH (2003) cutoff point was used, there was a marked increase in the proportion of respondents in the overweight categories by $2.7 \%$ and obesity class I by $12.8 \%$. The Indian (AdjOR 2.06, 95\% CI: 1.11, 3.83, $\mathrm{p}=0.021$ ) and Malay (AdjOR 1.75, 95\% CI: 1.02, 3.00, p=0.040) ethnicities, as well as both multiparity (AdjOR 1.46, 95\% CI: 1.23, 1.73, p <0.001) and grand multiparity (AdjOR 2.41, 95\% CI: $1.78,3.26, \mathrm{p}<0.001$ ), were significantly associated with maternal obesity. There were significant association between maternal obesity with hypertensive disorder in pregnancy $(\mathrm{p}=0.025)$, caesarean section delivery $(\mathrm{p}=0.002)$ and macrosomic infant $(\mathrm{p}<0.001)$.

Conclusion: The identification of risk factors for maternal obesity is important to facilitate intervention programmes focused on improving the pregnancy outcomes for a high-risk group of women.

\section{Introduction}

The prevalence of obesity is increasing at an alarming rate across all populations and age groups, which has resulted in important public health concerns. According to the Global Burden of Disease (GBD) study, the number of overweight and obese people worldwide increased by nearly 3-fold over the past three decades (from 857 million in 1980 to 2.1 billion in 2013), with a higher prevalence of obese females than males. In Malaysia, the prevalence of overweight or obese adults continues to rise compared to National Health Morbidity Survey (NHMS)
III in $2006(28.6 \%, 14.2 \%)$, NHMS 2011 (29.4\%, 15.1\%) and NHMS 2015 (30.0\%, 17.7\%). Furthermore, Malaysia has the highest prevalence of obesity in South East Asia. According to NHMS 2019, one in two (50.1\%) adults (aged 18 years and above) in Malaysia was either overweight $(30.4 \%)$ or obese $(19.7 \%)$, with a higher prevalence obese females $(38.8 \%)$ than males $(29.0 \%)$. Indian ethnicity had the highest prevalence of obesity (45.1\%).

The increasing rate of obesity among women of reproductive age is a growing public health 
Noraihan Mohd Nordin

FRCOG (Lon), MMedSci in ART U of Notts UK

Department of Obstetrics and

Gynaecology, Tunku Azizah Hospital

Women and Children Hospital, Kuala Lumpur, Ministry of Health, Malaysia

\section{Mohamad Farouk Abdullah}

MBBS (Malaya), FRCOG (London)

Perdana University Graduate School

of Medicine, Perdana University

Kuala Lumpur, Malaysia

\section{Nadiah Sa'at}

Bac Sc Mathematics (UPM)

Centre for Coordination of Clinical

Research Network, Institute Clinical

Research, National Institute of Heath

Ministry of Health, Malaysia issue. In Uganda, there has been a steady rise in the prevalence of overweight and obese women aged 15-49 years. ${ }^{1}$ A community-based crosssectional study in Selangor showed that the prevalence of obesity among women in the reproductive age group (20-49) was $15.3 \% .^{2}$ The increasing rates of obesity among women of child-bearing potential (WOCBP) will cause more women to begin their pregnancy with a higher BMI, resulting in maternal obesity. These women are more likely to develop pregnancy complications, such as gestational diabetes, hypertensive disorders of pregnancy, and caesarean section delivery. ${ }^{3}$ The consequences of this higher maternal and neonatal morbidity, ${ }^{4}$ with its increased resource utilisation and significant cost, ${ }^{5}$ present critical challenges for maternity healthcare services related to the prevention and management of these risks.

The rise in global obesity rates has shown a similar trend among pregnant mothers. Globally, it is estimated that there are 38.9 million overweight and obese pregnant women. The majority of overweight and obese pregnant women live in upper and lower middle income countries, ${ }^{6}$ including Malaysia. In England, a cross-sectional study involving 619323 births between 1989 and 2007 showed that maternal obesity is significantly increasing over time, having more than doubled from 7.6 to $15.6 \%$ over 19 years. $^{7}$ In Malaysia, NHMS 2016 showed that the prevalence of maternal obesity was $14.6 \%$, while mothers of advanced age (45-49) exhibited the highest prevalence of obesity (69.2\%). The majority of obese mothers were of Malay ethnicity (16.8\%), followed by Indian $(15.6 \%)$ and Chinese $(5.8 \%)$. The increasing prevalence of maternal obesity is an alarming issue since it represents a major challenge for obstetric practice.

According to the Centre for Maternal and Child Enquiries (CMACE) and the Royal College of Obstetricians and Gynaecologists (RCOG), in obstetric populations, an obese mother is defined as having a BMI equal to or greater than $30 \mathrm{~kg} / \mathrm{m}^{2}$, which is similar to that of the general population. Ideally, BMI should be calculated in the first trimester (i.e., before the mean maternal weight or body composition begin to change). The National Institute for Health and Care Excellence (NICE) antenatal care guideline (2008) and Kurowski ${ }^{8}$ recommend that maternal height and weight should be recorded for all women at their initial booking visit (i.e., at less than
10-12 weeks gestation) to allow the calculation of BMI. This is because self-reported height is often overestimated and self-reported weight underestimated, particularly among obese women. Notably, this could lead to an inaccurate risk assessment during pregnancy. ${ }^{9}$

Maternal obesity increases the risk of maternal death due to complications that arise during pregnancy and labour. According to the Confidential Enquiry into Maternal Child Health (CEMAH) 2003-2005 report, more than half of maternal deaths were due to direct or indirect causes of being either overweight or obese, with more than $15 \%$ of mothers being morbidly obese. Furthermore, the major direct causes of maternal mortality worldwide include haemorrhage, high blood pressure, infection and obstructed labour-all of which are associated with maternal obesity. ${ }^{3}$

Published studies on maternal obesity in Malaysia remain in their infancy. Thus, there are very few studies regarding the prevalence of maternal obesity in Malaysia. A cross-sectional study of four antenatal clinics in Seremban showed that more than half of respondents were overweight or obese (60.6\%). ${ }^{10}$ Moreover, another retrospective cross-sectional study of 72 health clinics in Selangor found that the prevalence of maternal obesity was $28.3 \%{ }^{11}$

To our knowledge, there is no published study available on factors associated with maternal obesity by the Malaysian National Obstetric Registry (NOR). Therefore, this study aimed to examine the proportion, associated factors and outcomes of maternal obesity among pregnant women in Klang Valley using the NOR database. Identifying the proportion of maternal obesity among pregnant women and its associated factors can provide insights and facilitate health monitoring and evidence-based policies for preventive measures to improve maternal health and pregnancy outcomes. The findings from this study can also be used as a baseline to guide upcoming studies in this field as well as intervention programmes to improve maternal and fetal health, particularly in Malaysia.

\section{Methods}

Study design and setting

The present study applied a cross-sectional study design based on a retrospective data review between January and March 2018 in the Clinical Research Center (CRC) of Kuala Lumpur Hospital. 
Data were collected from the Malaysian NOR. The NOR is an online registry that was created by the Ministry of Health in 2009 to monitor obstetric populations in Malaysia. A total of 14 tertiary hospitals and 1 district hospital across Peninsular Malaysia and East Malaysia contribute data to the NOR. Each hospital has a dedicated coordinator, Obstetrics and Gynaecology specialist or consultant and a nursing coordinator to monitor data entry. Klang Valley, which has two tertiary hospitals, was selected as the context for this study. Klang Valley is an urban conglomeration in Malaysia that is centred in Selangor, Kuala Lumpur, Putrajaya. Its surroundings and suburbs are naturally delineated by hilly areas and the Port Klang coastline.

\section{Study Participants}

The reference populations comprised pregnant women in Klang Valley. The study sample included pregnant women in Klang Valley who registered in the NOR 2015 and met the inclusion and exclusion criteria. In this study, the inclusion criteria were pregnant women who delivered a singleton newborn, booking done $\leq 12$-week period of amenorrhea and had a cephalic presentation. The exclusion criteria were incomplete data with the absence of either weight or height data, unrealistic values due to erroneous data entry, the absence of gestational age during booking and those with pre-existing comorbidities (e.g., diabetes mellitus type 1 or type 2, chronic hypertension and chronic kidney disease) since pre-existing comorbidities may affect maternal and fetal outcomes analysis.

The sample size was calculated for each variable of associated factors for maternal obesity using the power and sample size calculation to compare two independent proportions. The largest estimated sample for each group was 2129 based on the proportion of normal BMI among pregnant women of Indian ethnicity $\left(\mathrm{P}_{0}\right)$ being $0.08,{ }^{12}$ the estimated proportion of maternal obesity for Indian ethnicity $\left(\mathrm{P}_{1}\right)$ being $0.12,5 \%$ type 1 error, $80 \%$ power, $\mathrm{M}$ (ratio between exposed and non-exposed subjects) of 2 and an additional $10 \%$ of missing data being applied in the data analysis.

\section{Data Collection and Analysis}

Notably, this study involved secondary data collection. The retrieved information includes socio-demographic details, including mother's age, ethnicity, marital status, household income, and smoking status as well as obstetric characteristics (i.e., parity, maternal weight, height, BMI and period of amenorrhea during booking).

BMI was calculated by weight in kilograms divided by height in metres squared. For descriptive analysis, the BMI values were classified into six categories based on the World Health Organization (WHO 1995) and Malaysian Clinical Practice Guidelines on Management of Obesity (MOH 2003) cut-off points. BMI values were calculated based on weights and heights documented at booking $\leq 12$-week period of amenorrhea. ${ }^{9,13}$ To determine the factors associated with maternal obesity and its outcomes, the WHO (1995) BMI classification was used as an international comparison due to limited evidence available for using different BMI cut-off points for pregnant Asian mothers. ${ }^{12}$ In this study, normal BMI was identified as $18.5-24.9 \mathrm{~kg} / \mathrm{m}^{2}$. For the obese group, the BMI values for overweight and obese were grouped. Data for underweight individuals were excluded from further analysis since the main research question relates to maternal obesity and its associated factors.

The independent variables were categorised according to age (i.e., $<35$ and $\geq 35$ years) and ethnicity was divided into five main groups (i.e., Malay, Chinese, Indian, other ethnicity and foreigner) according to NOR classifications. Murut, Bajau, Iban, Dusun, Melanau, Bidayuh, Kadazan, other indigenous groups in Sabah and Sarawak (East Malaysia), as well as Orang Asli (Peninsular Malaysia), were categorised as 'other ethnicity'. Household income was classified as either low (<RM5000), middle (RM5000-9999) or high $(\geq \mathrm{RM} 10,000)$. Parity was classified as either nulliparous, multiparous or grand multiparous (parity $\geq 5$ ). Marital status was classified as either married or single. Smoking status was divided into smoking and nonsmoking. Booking details include maternal weight, height and BMI during booking. Maternal outcomes include gestational diabetes mellitus, hypertensive disorder in pregnancy, instrumental delivery, caesarean section and post-partum haemorrhage. Fetal outcomes include intrauterine growth restriction (IUGR), macrosomic baby, shoulder dystocia, preterm delivery, congenital abnormalities, low Apgar score and fetal death. 
Statistical Package for Social Science (SPSS) version 22.0 statistical software was used for data entry and analysis. Descriptive statistics with mean and standard deviation (SD), frequency and percentages were calculated. Simple and multiple logistic regression analyses were used to determine factors associated with maternal obesity, while the association between maternal obesity and adverse maternal and fetal outcomes was assessed by using Pearson's chisquared test. Maternal BMI status was based on the WHO (1995) cut-off point for both analyses.

Multiple logistic regression was performed using the forward selection and backward elimination method, followed by the manual retention or removal of the independent variables remaining in the model based on their clinical importance. The output between models was then compared and the best model was selected. In this study, the single dichotomous outcome was coded as 0 for nonobese (normal) and 1 for obese (overweight and obese). Simple logistic regression was performed to select the variables for multiple logistic regression analysis, and only variables with a p-value $<0.25$ or clinical importance were selected. The factors included in the multiple logistic regression were age, ethnicity and parity. Multicollinearity between different predictor variables was checked using the variance inflation factor (VIF). Notably, a VIF value of $<5.0$ indicates no multicollinearity. All possible two-way interaction terms between significant variables were checked individually. The final model that gave the best fit and was parsimonious as well as biologically sound was selected. The adjusted odds ratio was estimated with a 95\% confidence interval. A p-value of
$<0.05$ was considered statistically significant. The association between maternal obesity and adverse maternal and fetal outcomes was assessed by using Pearson's Chi-Square test to compare maternal and fetal outcomes between two categories of maternal BMI.

\section{Ethical approval}

Ethical clearance approval for this study was obtained from the Medical Research and Ethics Committee and Human Research Ethics Committee of Universiti Sains Malaysia (JePeM Code: USM/JePeM/17120720) and the Medical Research and Ethics Committee (MREC), Ministry of Health Malaysia (NMRR -17-3038-39050).

\section{Results}

Proportion of the study population

After applying the inclusion and exclusion criteria, the total sample retrieved from the registry for descriptive analysis included 2113 respondents. In the subsequent analysis for factors associated with maternal obesity, only 1964 respondents were retained for analysis since the underweight category was excluded.

According to the WHO (1995) BMI cutoffs points, $149(7.1 \%)$ respondents were underweight, $881(41.7 \%)$ were of normal weight, $604(28.6 \%)$ were overweight, 336 $(15.9 \%)$ were in obese class I, 98 (4.6\%) were in obese class II and $45(2.1 \%)$ were in obese class III. However, when the Malaysian Clinical Practice Guidelines on Management of Obesity (MOH 2003) were used, there was a marked increase in the proportion of the overweight by $2.7 \%$ and obese class I groups by $12.8 \%$ (Table 1).

Table 1. Proportions of maternal BMI classifications according to the WHO (1995) and MOH (2003) cut-off points $(\mathrm{n}=2113)$.

\begin{tabular}{l|l|l|l}
$\begin{array}{l}\text { BMI classification } \\
\text { WHO (1995) cut-off point }\end{array}$ & n (\%) & $\begin{array}{l}\text { BMI classification } \\
\text { MOH (2003) cut-off point }\end{array}$ & n (\%) \\
\hline Underweight $(<18.5)$ & $149(7.1)$ & Underweight $(<18.5)$ & $149(7.1)$ \\
\hline Normal $(18.5-24.9)$ & $881(41.7)$ & Normal $(18.5-22.9)$ & $554(26.2)$ \\
\hline Overweight $(25-29.9)$ & $604(28.6)$ & Overweight $(23-27.4)$ & $662(31.3)$ \\
\hline Obese class I (30-34.9) & $336(15.9)$ & Obese class I (27.5-34.9) & $605(28.7)$ \\
\hline Obese class II $(35-39.9)$ & $98(4.6)$ & Obese class II $(35-39.9)$ & $98(4.6)$ \\
\hline Obese class III $(\geq 40.0)$ & $45(2.1)$ & Obese class III $(\geq 40.0)$ & $45(2.1)$ \\
\hline
\end{tabular}

\section{Maternal characteristics}

The maternal characteristics of the respondents are presented in Table 2. In general, the majority of respondents were of Malay ethnicity (78.3\%), younger than 35 years old (85.0\%), married (99.5\%) and multiparous (55.1\%). Furthermore, $83.1 \%$ had low income and only $0.2 \%$ of the study population were smoking. 
Table 2. Maternal characteristics of pregnant women in Klang Valley $(\mathrm{n}=2113)$.

\begin{tabular}{|c|c|c|c|c|c|}
\hline \multirow[b]{2}{*}{ Variables } & \multirow{2}{*}{$\begin{array}{l}\text { Total } \\
\text { n (\%) }\end{array}$} & \multicolumn{4}{|c|}{ Maternal BMI (n, \%) } \\
\hline & & $\begin{array}{l}\text { Underweight } \\
\quad(\mathrm{n}=149)\end{array}$ & $\begin{array}{c}\text { Normal } \\
(\mathrm{n}=\mathbf{8 8 1})\end{array}$ & $\begin{array}{l}\text { Overweight } \\
(\mathrm{n}=604)\end{array}$ & $\begin{array}{c}\text { Obese } \\
(\mathrm{n}=479)\end{array}$ \\
\hline $\begin{array}{l}\text { Age (years) } \\
<35 \\
\geq 35\end{array}$ & $\begin{array}{c}1814(85.8) \\
299(14.2)\end{array}$ & $\begin{array}{c}144(96.6) \\
5(3.4)\end{array}$ & $\begin{array}{l}772(87.6) \\
109(12.4)\end{array}$ & $\begin{array}{l}517(85.6) \\
87(14.4)\end{array}$ & $\begin{array}{c}381(79.5) \\
98(20.5)\end{array}$ \\
\hline $\begin{array}{l}\text { Ethnicity } \\
\text { Malay } \\
\text { Chinese } \\
\text { Indian } \\
\text { Other ethnicity } \\
\text { Foreigner }\end{array}$ & $\begin{array}{c}1654(78.3) \\
60(2.8) \\
173(8.2) \\
68(3.2) \\
158(7.5) \\
\end{array}$ & $\begin{array}{c}117(78.5) \\
3(2.0) \\
14(9.4) \\
1(0.7) \\
14(9.4) \\
\end{array}$ & $\begin{array}{c}666(75.6) \\
33(3.7) \\
63(7.2) \\
29(3.3) \\
90(10.2) \\
\end{array}$ & $\begin{array}{c}482(79.8) \\
18(3.0) \\
52(8.6) \\
18(3.0) \\
34(5.6)\end{array}$ & $\begin{array}{c}389(81.2) \\
6(1.2) \\
44(9.2) \\
20(4.2) \\
20(4.2) \\
\end{array}$ \\
\hline $\begin{array}{l}\text { Household income } \\
\text { High } \\
\text { Middle } \\
\text { Low } \\
\end{array}$ & $\begin{array}{c}33(1.6) \\
324(15.3) \\
1756(83.1)\end{array}$ & $\begin{array}{c}1(0.7) \\
24(16.1) \\
124(83.2)\end{array}$ & $\begin{array}{c}14(1.6) \\
129(14.6) \\
738(83.8)\end{array}$ & $\begin{array}{c}13(2.2) \\
98(16.2) \\
493(81.6)\end{array}$ & $\begin{array}{c}5(1.1) \\
73(15.2) \\
401(83.7)\end{array}$ \\
\hline $\begin{array}{l}\text { Parity } \\
\text { Nulliparous } \\
\text { Multiparous } \\
\text { Grand multiparous }\end{array}$ & $\begin{array}{c}769(36.4) \\
1156(54.7) \\
188(8.9)\end{array}$ & $\begin{array}{c}70(47.0) \\
74(49.7) \\
5(3.3) \\
\end{array}$ & $\begin{array}{c}365(41.4) \\
463(52.6) \\
53(6.0)\end{array}$ & $\begin{array}{c}198(32.8) \\
344(57.0) \\
62(10.2)\end{array}$ & $\begin{array}{c}136(28.4) \\
275(57.4) \\
68(14.2)\end{array}$ \\
\hline $\begin{array}{l}\text { Marital status } \\
\text { Married } \\
\text { Single }\end{array}$ & $\begin{array}{c}2103(99.5) \\
10(0.5)\end{array}$ & $\begin{array}{c}148(99.3) \\
1(0.7) \\
\end{array}$ & $\begin{array}{c}878(99.7) \\
3(0.3) \\
\end{array}$ & $\begin{array}{c}600(99.3) \\
4(0.7) \\
\end{array}$ & $\begin{array}{c}477 \text { (99.6) } \\
2(0.4)\end{array}$ \\
\hline $\begin{array}{l}\text { Smoking status } \\
\text { Non-smoking } \\
\text { Smoking }\end{array}$ & $\begin{array}{c}2109(99.8) \\
4(0.2)\end{array}$ & $\begin{array}{c}149(100.0) \\
0(0.0)\end{array}$ & $\begin{array}{c}878(99.7) \\
3(0.3) \\
\end{array}$ & $\begin{array}{c}603(99.8) \\
1(0.2)\end{array}$ & $\begin{array}{c}479(100.0) \\
0(0.0)\end{array}$ \\
\hline
\end{tabular}

Household income (<RM5000: Low; RM5000-9999: Middle; $\geq$ RM 10000: High).1 USD is equivalent to RM 4.16 as of 7th July 2021.

\section{Factors associated with maternal obesity}

A simple logistic regression showed that age, ethnicity and parity were associated with maternal obesity. Age 35 and above (crude OR 1.46, 95\% CI: 1.13, 1.88, p = 0.004) as well as Malay (crude OR 1.80, 95\% CI: 1.05, 3.07, p = 0.032) and Indian ethnicity (crude OR 2.10, 95\% CI: $1.13,3.87, \mathrm{p}=0.018$ ) were significantly associated with maternal obesity. Regarding parity, multiparous (crude OR 1.46, 95\% CI: 1.21, 1.78, p <0.001) and grand multiparous (crude OR 2.68, 95\% CI: $1.89,3.81, \mathrm{p}<0.001$ ) were also found to be significantly associated with maternal obesity. Notably, there were no significant associations between household income, marital status and smoking with maternal obesity. The results are summarised in Table 3.

Table 3. Simple logistic regression of factors associated with maternal obesity $(n=1964)$.

\begin{tabular}{|c|c|c|c|c|}
\hline Variables & $\begin{array}{l}\text { Regression } \\
\text { coefficient B }\end{array}$ & $\begin{array}{l}\text { Crude OR } \\
(95 \% \mathrm{CI})\end{array}$ & $\begin{array}{l}\text { Wald statistic } \\
\text { (df) }\end{array}$ & $p$-value \\
\hline $\begin{array}{l}\text { Age (years) } \\
<35 \\
\geq 35\end{array}$ & 0.38 & $\begin{array}{c}1 \\
1.46(1.13,1.88)\end{array}$ & $8.40(1)$ & 0.004 \\
\hline $\begin{array}{l}\text { Ethnicity } \\
\text { Chinese } \\
\text { Malay } \\
\text { Indian } \\
\text { Other ethnicity } \\
\text { Foreigner }\end{array}$ & $\begin{array}{r}0.59 \\
0.74 \\
0.59 \\
-0.19 \\
\end{array}$ & $\begin{array}{c}1 \\
1.80(1.05,3.07) \\
2.10(1.13,3.87) \\
1.80(0.88,3.68) \\
0.55(0.83,0.44)\end{array}$ & $\begin{array}{l}4.62(1) \\
5.57(1) \\
2.61(1) \\
0.36(1)\end{array}$ & $\begin{array}{l}\mathbf{0 . 0 3 2} \\
\mathbf{0 . 0 1 8} \\
\mathbf{0 . 1 0 6} \\
0.546 \\
\end{array}$ \\
\hline $\begin{array}{l}\text { Household income } \\
\text { High } \\
\text { Middle } \\
\text { Low }\end{array}$ & $\begin{array}{c}0.03 \\
-0.06\end{array}$ & $\begin{array}{c}1 \\
1.03(0.49,2.15) \\
0.94(0.47,1.91)\end{array}$ & $\begin{array}{l}0.01(1) \\
0.03(1)\end{array}$ & $\begin{array}{l}0.935 \\
0.869 \\
\end{array}$ \\
\hline $\begin{array}{l}\text { Parity } \\
\text { Nulliparous } \\
\text { Multiparous } \\
\text { Grand multiparous }\end{array}$ & $\begin{array}{l}0.38 \\
0.99\end{array}$ & $\begin{array}{c}1 \\
1.46(1.21,1.78) \\
2.68(1.89,3.81)\end{array}$ & $\begin{array}{l}15.11(1) \\
30.10(1)\end{array}$ & $\begin{array}{l}<0.001 \\
<0.001\end{array}$ \\
\hline $\begin{array}{l}\text { Marital status } \\
\text { Single } \\
\text { Married }\end{array}$ & -0.49 & $0.61(0.15,2.46)$ & $0.48(1)$ & 0.490 \\
\hline $\begin{array}{l}\text { Smoking status } \\
\text { Non-smoking } \\
\text { Smoking }\end{array}$ & -1.31 & $\begin{array}{c}1 \\
0.27(0.33,2.61)\end{array}$ & $1.28(1)$ & 0.258 \\
\hline
\end{tabular}


Multiple logistic regression analysis showed that maternal ethnicity and parity were significantly associated with maternal obesity (see Table 4). Malay ethnicity has 1.75 times the odds compared to Chinese to have maternal obesity (95\% CI: 1.02, 3.00, p = 0.040), while Indian ethnicity has 2.06 times the odds compared to Chinese to have maternal obesity (95\% CI: 1.11, 3.83, p $=0.021)$ when adjusted for parity. Moreover, multiparous has 1.46 times the odds compared to nulliparous to have maternal obesity (95\% CI: $1.23,1.73, \mathrm{p}<0.001)$, while a grand multiparous has 2.41 times the odds compared to nulliparous to have maternal obesity (95\% CI: 1.78, 3.26, p $<0.001$ ) when adjusted for ethnicity.

Table 4. Multiple logistic regression of factors associated with maternal obesity $(\mathrm{n}=1964)$.

\begin{tabular}{|c|c|c|c|c|}
\hline Variables & $\begin{array}{l}\text { Regression } \\
\text { coefficient (B) }\end{array}$ & $\begin{array}{l}\text { Crude OR } \\
(95 \% \text { CI })\end{array}$ & $\begin{array}{l}\text { Wald statistic } \\
(d f)\end{array}$ & $p$-value \\
\hline $\begin{array}{l}\text { Ethnicity } \\
\text { Chinese } \\
\text { Malay } \\
\text { Indian } \\
\text { Other ethnicity } \\
\text { Foreigner }\end{array}$ & $\begin{array}{c}0.56 \\
0.72 \\
0.60 \\
-0.18\end{array}$ & $\begin{array}{c}1 \\
1.75(1.02,3.00) \\
2.06(1.11,3.83) \\
1.82(0.88,3.73) \\
0.83(0.44,1.56)\end{array}$ & $\begin{array}{l}4.13(1) \\
5.24(1) \\
2.63(1) \\
0.33(1)\end{array}$ & $\begin{array}{l}\mathbf{0 . 0 4 0} \\
\mathbf{0 . 0 2 1} \\
0.106 \\
0.568\end{array}$ \\
\hline $\begin{array}{l}\text { Parity } \\
\text { Nulliparous } \\
\text { Multiparous } \\
\text { Grand multiparous }\end{array}$ & $\begin{array}{l}0.38 \\
0.95\end{array}$ & $\begin{array}{c}1 \\
1.46(1.23,1.73) \\
2.41(1.78,3.26)\end{array}$ & $\begin{array}{l}15.28(1) \\
27.61(1)\end{array}$ & $\begin{array}{l}<0.001 \\
<0.001\end{array}$ \\
\hline
\end{tabular}

Constant $=-0.591$.

Forward LR method was applied.

No multicollinearity and no interaction.

Hosmer-Lemeshow test: $\mathrm{p}$-value $=0.066$.

Classification table: $57.8 \%$ correctly classified.

Area under Receiver Operating Characteristics (ROC) curve was 59.0\%.

\section{Association between maternal obesity and adverse feto-maternal outcomes}

The associations between maternal obesity and feto-maternal outcomes are summarised in Table 5. For maternal outcomes, there was a significant association between maternal obesity and hypertensive disorder in pregnancy $(\mathrm{p}=0.025)$ and caesarean section delivery $(\mathrm{p}=0.002)$. There was no significant association between maternal obesity and gestational diabetes mellitus and post-partum haemorrhage. For fetal outcomes, there was a significant association between maternal obesity and macrosomic infant $(p<0.001)$. However, no significant associations for IUGR, shoulder dystocia, prematurity, congenital malformation, low Apgar score and fetal death were observed.

Table 5. Association between maternal obesity and adverse fetal and maternal outcomes $(\mathrm{n}=1964)$.

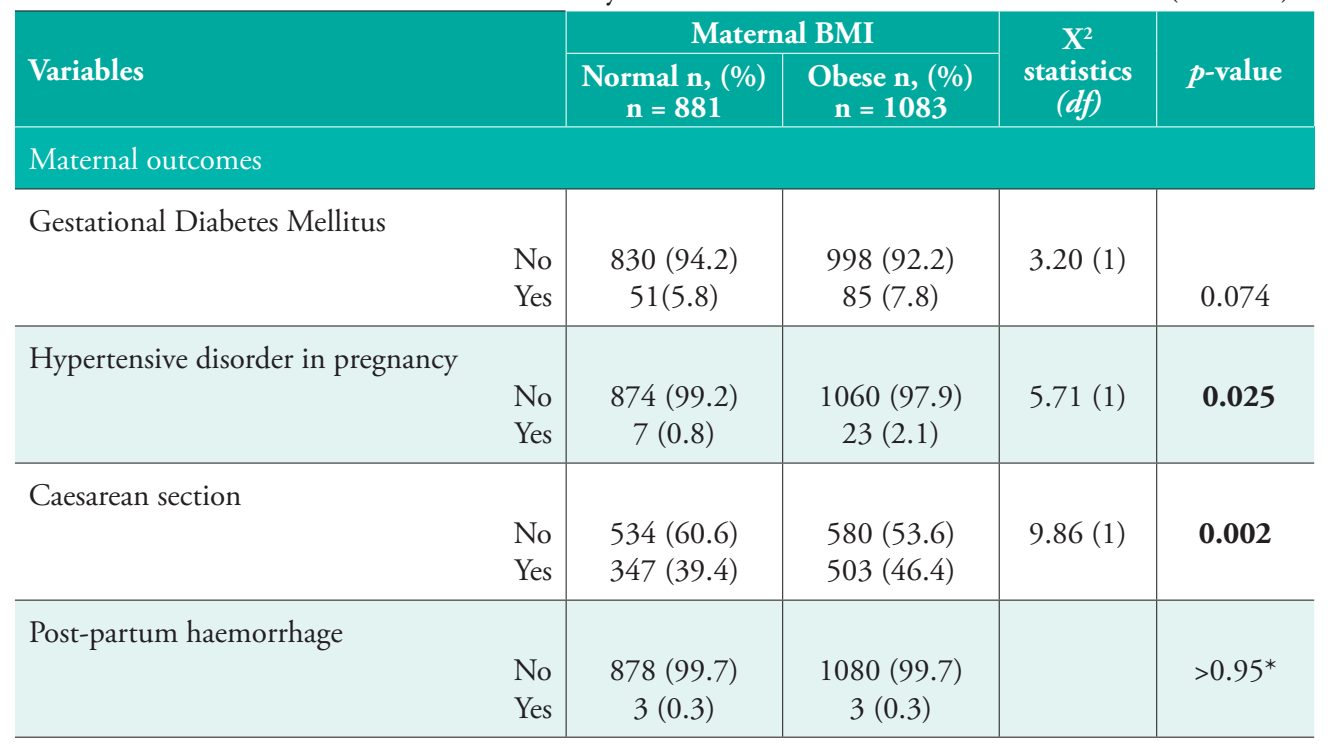




\begin{tabular}{|c|c|c|c|c|c|}
\hline \multirow[b]{2}{*}{ Variables } & & \multicolumn{2}{|c|}{ Maternal BMI } & \multirow{2}{*}{$\begin{array}{c}\mathrm{X}^{2} \\
\text { statistics } \\
(d f)\end{array}$} & \multirow[b]{2}{*}{$p$-value } \\
\hline & & $\begin{array}{l}\text { Normal n, (\%) } \\
\quad \mathbf{n}=\mathbf{8 8 1}\end{array}$ & $\begin{array}{c}\text { Obese } n,(\%) \\
n=1083\end{array}$ & & \\
\hline \multicolumn{6}{|c|}{ Fetal outcomes } \\
\hline IUGR & $\begin{array}{l}\text { No } \\
\text { Yes }\end{array}$ & $\begin{array}{c}869(98.6) \\
12(1.4)\end{array}$ & $\begin{array}{c}1072(99.0) \\
11(1.0)\end{array}$ & $0.51(1)$ & 0.531 \\
\hline Macrosomi & $\begin{array}{l}\text { No } \\
\text { Yes }\end{array}$ & $\begin{array}{c}872(99.0) \\
9(1.0)\end{array}$ & $\begin{array}{c}1044(96.4) \\
39(3.6)\end{array}$ & $13.56(1)$ & $<0.001$ \\
\hline Prematurit & $\begin{array}{l}\text { No } \\
\text { Yes }\end{array}$ & $\begin{array}{c}846(96.0) \\
35(4.0)\end{array}$ & $\begin{array}{c}1047(96.7) \\
36(3.3)\end{array}$ & $0.587(1)$ & 0.444 \\
\hline Congenital & $\begin{array}{l}\text { No } \\
\text { Yes }\end{array}$ & $\begin{array}{c}881(100.0) \\
0(0.0)\end{array}$ & $\begin{array}{c}1081(99.8) \\
2(0.2)\end{array}$ & & $0.505^{*}$ \\
\hline Low Apgar & $\begin{array}{l}\text { No } \\
\text { Yes }\end{array}$ & $\begin{array}{c}870(98.8) \\
11(1.2)\end{array}$ & $\begin{array}{c}1066(98.4) \\
17(1.6)\end{array}$ & $0.356(1)$ & 0.573 \\
\hline Fetal death & $\begin{array}{l}\text { No } \\
\text { Yes }\end{array}$ & $\begin{array}{c}879(99.8) \\
2(0.2)\end{array}$ & $\begin{array}{c}1075(99.3) \\
8(0.7)\end{array}$ & & $0.200^{*}$ \\
\hline
\end{tabular}

*Fisher's exact test.

\section{Discussion}

Proportion of maternal obesity

The increasing prevalence of obesity is a serious matter that is having an impact on morbidity worldwide. Globally, the proportion of maternal obesity ranges from 10.1 to $17.9 \% .^{3,14}$ In the present study, $28.6 \%$ of pregnant women were overweight, while $22.6 \%$ of them were categorised under maternal obesity when using the WHO (1995) cut-off point. The proportion of maternal obesity in this study was higher (22.6\%) than the national population survey (NHMS 2016), which reported a $14.6 \%$ prevalence. This was due to our study population being from two tertiary referral hospitals with specialised consultative care, where most higher-risk cases that have an association with maternal obesity (e.g., hypertensive disorder in pregnancy, gestational diabetes mellitus, etc.) were referred to. This resulted in a higher proportion of maternal obesity in this study when compared to the population-based survey. Nevertheless, we report a similar proportion of obesity among women $(20.6 \%)$ to the general population in Malaysia (NHMS 2015), which has also been observed in another study. ${ }^{15}$

This study also found that the proportion of overweight pregnant women increased to $31.3 \%$ and the proportion of maternal obesity increased to $35.4 \%$ when using the Malaysian Clinical Practice Guidelines on Management of Obesity (2003) cut-off point. A similar trend was found in Singapore, where the proportion of normal weight mothers was reduced by $16.1 \%$ and the proportion of overweight and obese increased by $7.4 \%$ and $8.8 \%$, respectively, following the use of the Asian BMI cut-off point. ${ }^{12}$

The WHO proposed a lower BMI cut-off point for Asians to indicate that the risk of cardiovascular mortality begins to rise at lower cut-off points in this general population. ${ }^{16,17}$ However, evidence for using different cut-off points among pregnant Asian mothers, as well as their associations (including complications), remains in its infancy. ${ }^{12,18,19}$

\section{Factors associated with maternal obesity}

Our study shows that two major ethnic groups in Malaysia were associated with maternal obesity. In comparison to Chinese ethnicity as a reference group, Indian ethnicity is 2.1 times more likely to become obese in pregnancy, followed by Malay. These findings are in line with a study from Singapore, where Ying Pang, Loy, and Tan showing that maternal obesity was common among Malay (21.5\%) and Indian (17.2\%) when compared to Chinese (4.6\%). ${ }^{12}$ NHMS 2015 showed 
a similar trend with a higher prevalence of obesity among women, those of Indian and Malay ethnicity; and the majority were at reproductive-age group resulting them to begin their pregnancy as obese once conceived. On the contrary, few studies have shown that maternal obesity was associated with minority ethnic groups. In the UK and Queensland, studies have shown an increased likelihood of being overweight and obese among black ${ }^{7}$ and indigenous women, respectively. ${ }^{20}$ Heslehurst et al. found no significant association between ethnicity and maternal obesity. However, the interpretation of this finding was limited since the numbers representing non-Caucasian populations were relatively low. ${ }^{15}$ The observed ethnic differences in the association between ethnicity and obesity may be attributed to differences in genetic predisposition as well as developmental and environmental factors. ${ }^{21}$ Additionally, Bahadoer et al. found that lifestyle- and pregnancy-related characteristics explained up to $40 \%$ of the associations. In our study, the diversity in cultural background and food consumption characterised by the three predominant ethnic groups in Malaysia (i.e., Malay, Chinese and Indian) results in a complex multiracial population. A mixedmethod study of excessive weight gain among Malay people in Kelantan by Farhana et al. (2018) reported the perception of pregnancy as a time to gain weight freely, which is largely due to social norms of acceptability regarding excessive weight gain in pregnancy that commonly cite 'eating for two' and view pregnancy as a time to 'enjoy' or 'relax'. A similar finding was observed among multiethnic pregnant women in Singapore. ${ }^{22}$ These norms result in post-partum weight retention and maternal obesity upon entering a subsequent pregnancy. Therefore, a targeted approach that is culturally sensitive is important in addressing this issue among multi-ethnic populations. ${ }^{23}$

In this study, pregnant women who had higher parity were significantly associated with obesity. After controlling for ethnicity, grand multiparous women have a more than two times greater risk of becoming obese compared to nulliparous women. Another study showed similar results for the relationship between maternal obesity and increasing parity. ${ }^{24}$ This parity-related obesity burden can be explained by weight gain during pregnancy. A prospective cohort study of 638 mothers in Malaysia showed that $33.8 \%$ of respondents retained substantial weight ( $\geq 5 \mathrm{~kg}$ above preconception weight), while gestational weight gain of $\geq 12 \mathrm{~kg}$ was significantly associated with higher 6-month post-partum weight retention. Therefore, such women are more likely to exhibit maternal obesity when entering their next pregnancy. ${ }^{25}$ Furthermore, the requirement for energy storage depends on maternal pre-pregnancy body size. As such, the intake of excess energy beyond the requirements for a growing fetus would be stored, resulting in increased body fat composition with subsequent pregnancies. ${ }^{26}$

Although our univariable analysis showed that age was associated with maternal obesity, it was not statically significant in the final model of logistic regression. Additionally, household income, marital status and smoking were not associated with maternal obesity, which has also been observed in a previous study. ${ }^{27}$ However, careful interpretation is required for these variables since there was a relatively small number of unmarried and smoking women represented in the data. In contrast, few studies have shown that advanced maternal age, low income, married status and smoking are associated with maternal obesity. ${ }^{15,28}$

\section{Maternal and fetal outcomes with maternal obesity}

Our data suggest that there was a significant association between maternal obesity and hypertensive disorder in pregnancy (HDP). The prevalence of HDP in this study was lower when compared to findings in the Malaysian national population survey $(5.8 \%)$ (NHMS 2016). Similar findings from a case-control study conducted in Tehran reported that obese mothers had a 4.5-fold greater risk of developing HDP. ${ }^{29}$ Additionally, Bodnar et al. reported that the adjusted risk of pre-eclampsia doubled at a BMI of $26 \mathrm{~kg} / \mathrm{m}^{2}$ and nearly tripled at BMI values of $30 \mathrm{~kg} / \mathrm{m}^{2}$ and above. ${ }^{30}$ The pathophysiology for the stated association was related to the low level of adiponectin, increased leptin level, insulin resistance, inflammatory upregulation, prothrombotic changes, abnormal placental vasculature and endothelial dysfunction ${ }^{31}$ found in obese women with hypertensive disorder, particularly severe pre-eclampsia. ${ }^{32}$ HDP was associated with both maternal and perinatal mortality and morbidity as well as an elevated risk of cardiovascular and metabolic disease later in life. ${ }^{33}$

This study found that there was a significant association between maternal obesity and 
caesarean delivery. The caesarean rate in this study was higher than the caesarean rate recommended by the WHO (10-15\%). ${ }^{34}$ Specifically, there was a significant association between maternal obesity and emergency caesarean section $(p=0.002)$ (result not shown). A meta-analysis involving 33 studies reported that the unadjusted ratios of caesarean delivery among overweight, obese and severely obese women were 1.46 (95\% CI: 1.34, 1.60), 2.05 (95\% CI: 1.86, 2.27) and 2.89 (95\% CI: 2.28, 3.79), respectively, when compared to pregnant women of normal weight. ${ }^{35}$ In the US, the incidence of caesarean delivery increased by $28.3 \%$ with increasing maternal BMI compared to lean. ${ }^{36}$ Although the mechanism of maternal obesity affecting the labour process is not well established, studies have suggested that obese pregnant women have a significantly longer labour duration and slower progress at the early part of the first stage of labour (a condition known as labour dystocia), which increases their risk of caesarean delivery due to poor labour progress. ${ }^{37}$ This situation is contributed by poor myometrium contractility in obese mothers. ${ }^{38}$ Additionally, the increased pelvic soft tissue in obese parturient women causes cephalopelvic disproportionation, which is also a predisposing factor for caesarean events. ${ }^{39}$

Our findings suggest that maternal obesity was associated with fetal macrosomia. This finding is supported by a systematic review and meta-analysis noting that obese mothers have a 2-fold greater risk of having macrosomic babies. ${ }^{40}$ Tanaka et al. reported that maternal obesity is an independent predictor of macrosomic infants, particularly from the third trimester through birth. ${ }^{41}$ Macrosomic infants are at higher risk of experiencing meconium aspiration, having a low Apgar score at 5 minutes, requiring assisted ventilation, subsequent NICU admission, and death. ${ }^{42}$ The fetal endocrine system contributes to fetal growth in response to maternal obesity. High insulin resistance was found in obese mothers and gestational diabetes mellitus mothers, which causes an increase in maternal nutrient availability (e.g., glucose and lipids) ${ }^{43,44}$ for the fetus. These resulting increases in neonatal insulin levels and other growth factor responses (e.g., leptin) lead to macrosomic infants. Furthermore, Sewell et al. reported that the macrosomic infants of obese mothers had a higher fat mass composition rather than lean body mass, thereby indicating that environmental (rather than genetic) factors pose a significant risk for offspring obesity and metabolic disorders later in life. ${ }^{45}$ There was no significant association between maternal obesity and Gestational Diabetes Mellitus, post-partum haemorrhage, IUGR, prematurity, congenital malformation, low Apgar score and fetal death.

It is anticipated the burden of maternal obesity will rise in the future since the prevalence of obesity among women of reproductive age is increasing, as seen in NHMS 2019. Obtaining insights into ethnic differences in maternal obesity and prevalence is important for the development of tailored preventive strategies that aim to improve both maternal and fetal outcomes. Notably, this is crucial to achieving the aims of the United Nations Sustainable Development Goals (SDGs) by 2030. Concentrated efforts need to prioritise high-risk groups to maximise their pregnancy outcomes. Based on our findings, preventive strategies should focus on reducing pre-pregnancy maternal overweight status and obesity among women of reproductive age as a form of primary prevention by strengthening pre-pregnancy care. This would ensure that women do not enter pregnancy as overweight or obese. Regarding secondary prevention, pregnant women achieving adequate gestational weight gain (GWG) is crucial to prevent excessive GWG that can cause increasing BMI with increasing parity. Interventions should be tailored to the sociocultural aspects identified in qualitative studies of multi-ethnic women in Malaysiaparticularly Indian and Malay women-to ensure their effectiveness. Additionally, to improve the quality of care, a guideline for the management of maternal obesity in primary care is essential since there are currently no specific guidelines for managing obesity among women of reproductive age in the Malaysian Clinical Practice Guidelines on Management of Obesity, or among obese pregnant women in the Malaysia Perinatal Care Manual. One relevant example is 'Queensland Clinical Guideline: Obesity in Pregnancy'. Furthermore, the Confidential Enquiry of Maternal Death (CEMD) in Malaysia needs to include specific analyses of maternal obesity as an attributable cause of maternal mortality so that the magnitude of the issue can be appreciated. Notably, this also applies to underfive mortality.

To our knowledge, this is the first study to report on the associations of both ethnicity 
and parity with maternal obesity using data from the NOR. Nevertheless, several limitations should be considered when interpreting this study. First, this study is based on data from the government tertiary referral centre. Thus, to avoid Berkson's bias, a population-based study is warranted. Second, the common problems encountered during research using secondary data include missing data and incomplete information. In this study, only $100 \%$ complete data were selected as part of the sample. Nevertheless, this study was able to obtain a sufficient sample size (based on the sample size calculation) and achieve a study power of $80 \%$. Third, other important determinants that contribute to maternal obesity (e.g., GWG, postpartum weight retention, physical activity and dietary intake) could not be explored using this data. Additionally, the outcome of maternal obesity in this study was analysed via univariable analysis. Thus, our results should be interpreted with caution since possible confounding effects were not controlled for. Nevertheless, our study provides insights into the association between maternal obesity and its outcomes. Lastly, further studies are recommended to identify appropriate cutoff-point for pre-pregnancy BMI to be used among Asian pregnant women and explore social phenomena among pregnant women of different ethnicities to gain a more wellrounded understanding of why certain ethnicities have a higher risk of exhibiting maternal obesity.
In conclusion, the proportion of maternal obesity in Klang Valley based on NOR data was $22.6 \%$ when WHO (1995) cut-off points were used. This proportion increased by $12.8 \%$ upon using the Malaysian Clinical Practice Guidelines on Management of Obesity (2003) cut-off points. In this study, the factors associated with maternal obesity were Indian and Malay ethnicity and higher parity. Based on the univariable analysis, maternal obesity was associated with adverse fetal and maternal outcomes that include HDP, caesarean section delivery and macrosomic baby. To achieve the aims of the SDGs by 2030, we must maximise our efforts to identify and overcome this modifiable risk factor through culturally sensitive means to further reduce maternal and neonatal morbidity and mortality and break the detrimental cycle of metabolic derangement in our future generation.

\section{Conflicts of Interest}

This research received no funding. The authors declare that there are no conflicts of interest.

\section{Acknowledgements}

The authors would like to thank the Director-General of Health, Malaysia for his permission to publish this article.

\section{References}

1. Yaya S, Ghose B. Trend in overweight and obesity among women of reproductive age in Uganda: 1995-2016. Obes Sci Pract. 2019;5(4):312-23.

2. Sidik SM, Rampal L. The prevalence and factors associated with obesity among adult women in Selangor, Malaysia. Asia Pac Fam Med. 2009;8(1):2.

3. Onubi OJ, Marais D, Aucott L, et al. Maternal obesity in Africa: A systematic review and meta-analysis. J Public Health. 2016;38(3):e218-e31.

4. Kristensen J, Vestergaard M, Wisborg K, et al. Pre-pregnancy weight and the risk of stillbirth and neonatal death. BJOG. 2005;112(4):403-8.
5. Morgan KL, Rahman MA, Macey S, et al. Obesity in pregnancy: A retrospective prevalence-based study on health service utilisation and costs on the NHS. BMJ Open. 2014;4:e003983

6. Chen C, Xu X, Yan Y. Estimated global overweight and obesity burden in pregnant women based on panel data model. PLoS ONE. 2018;13(8):e202183.

7. Heslehurst N, Rankin J, Wilkinson JR, et al. A nationally representative study of maternal obesity in England, UK: Trends in incidence and demographic inequalities in 619323 births, 1989-2007. Int J Obes. 2010;34(3):420-8.
8. Krukowski RA, Bursac Z, McGehee MA, et al. Exploring potential health disparities in excessive gestational weight gain. JWomens Health. 2013;22(6):494-500.

9. Inskip H, Crozier S, Baird J, et al. Measured weight in early pregnancy is a valid method for estimating pre-pregnancy weight. J Dev Orig Health Dis. 2020;13:1-9.

10. Leelavathi M, Danasamy RS. Knowledge of obesity related pregnancy risks among expectant mothers and its associated factors. Med J Malaysia. 2018;73(4):239-43. 
11. Logakodie S, Azahadi O, Fuziah P. Gestational diabetes mellitus: The prevalence, associated factors and foeto-maternal outcome of women attending antenatal care. Malays Fam Physician. 2017;12(2),9-17.

12. Ying Pang S, Loy E, Tan L-K. Maternal obesity: Prevalence, outcomes and evaluation of body mass index cut-off values in a multiethnic Asian obstetric population. JOD. 2016;102: 4-12.

13. Krukowski RA, West DS, DiCarlo M, et al. Are early first trimester weights valid proxies for preconception weight? BMC Pregnancy Childbirth. 2016;16(1):357.

14. Bogaerts A, Van den Bergh B, Nuyts E, et al Socio-demographic and obstetrical correlates of pre-pregnancy body mass index and gestational weight gain. Clin Obes. 2012;2(56):150-9.

15. Heslehurst N, Ells L, Simpson H, et al. Trends in maternal obesity incidence rates, demographic predictors, and health inequalities in 36821 women over a 15-year period. BJOG. 2007;114(2):187-94.

16. Ko GTC, Chan JCN, Chow C-C, et al. Effects of obesity on the conversion from normal glucose tolerance to diabetes in Hong Kong Chinese. Obes Res. 2004;12(6):889-95.

17. Deurenberg-Yap M, Schmidt G, van Staveren WA, et al. The paradox of low body mass index and high body fat percentage among Chinese, Malays and Indians in Singapore. Int J Obes. 2000;24(8):1011-7.

18. Nishikawa E, Oakley L, Seed PT, et al. Maternal BMI and diabetes in pregnancy: Investigating variations between ethnic groups using routine maternity data from London, UK. PLoS ONE. 2017;12(6):e0179332.

19. Ganeshan M, Bujang MA, Soelar SA, et al. Importance of adopting BMI classifications using public health action points to delineate obstetric risk factors resulting in worsening obstetric outcomes among Asian population. J Obstet Gynaecol India. 2018;68(3):173-8.
20. Thrift AP, Callaway LK. The effect of obesity on pregnancy outcomes among Australian Indigenous and non-Indigenous women. Med J Aust. 2014;201(10):592-5.

21. Kumunyika SK. Obesity in minority populations: An epidemiologic assessment. Obesity. 1994;2(2):166-82.

22. Loh AZH, Oen KQX, Koo IJY, et al. Weight management during pregnancy: A qualitative thematic analysis on knowledge, perceptions and experiences of overweight and obese women in Singapore. Glob Health Action. 2018;11(1):1499199.

23. Griner D, Smith TB. Culturally adapted mental health intervention: A meta-analytic review. Psychotherapy. 2006;43(4):531.

24. Hajiahmadi M, Shafi H, Delavar MA. Impact of parity on obesity: A cross-sectional study in Iranian women. Med Princ Pract. 2015;24(1):70-4.

25. Fadzil F, Shamsuddin K, Wan Puteh SE, et al. Predictors of postpartum weight retention among urban Malaysian mothers: A prospective cohort study. Obes Res Clin Pract. 2018;12(6):493-9.

26. King JC. Physiology of pregnancy and nutrient metabolism. Am J Clin Nutr. 2000;71(5):1218S-25S.

27. Bautista-Castańo I, Henriquez-Sanchez P, Alemán-Perez N, et al. Maternal obesity in early pregnancy and risk of adverse outcomes. PLoS ONE. 2013;8(11):e80410.

28. Callaway LK, Prins JB, Chang AM, et al. The prevalence and impact of overweight and obesity in an Australian obstetric population. Med J Aust. 2006;184(2):56-9.

29. Kazemian E, Sotoudeh G, Dorosty-Motlagh AR, et al. Maternal obesity and energy intake as risk factors of pregnancy-induced hypertension among Iranian women. J Health Popul Nutr. 2014;32(3):486-93.

30. Bodnar LM, Ness RB, Markovic N, et al. The risk of preeclampsia rises with increasing prepregnancy body mass index. Ann Epidemiol. 2005;15(7):475-82.
31. Bates DO. An unexpected tail of VEGF and PlGF in pre-eclampsia. Biochem Soc Trans. 2011;39(6):1576-82.

32. Callaway LK, O'Callaghan M, McIntyre HD. Obesity and the hypertensive disorders of pregnancy. Hypertens Pregnancy. 2009;28(4):473-93.

33. Steegers EAP, von Dadelszen P, Duvekot JJ, et al. Pre-eclampsia. The Lancet. 2010;376(9741):631-44.

34. World Health Organisation. WHO Statement on Caesarean Section Rates 2015 [23 December 2017]. Available from: http://apps. who.int/iris/bitstream/handle/10665/161442/ WHO_RHR_15.02_eng.pdf?sequence $=1$.

35. Chu S, Kim S, Schmid C, et al. Maternal obesity and risk of cesarean delivery: A metaanalysis. Obes Rev. 2007;8(5):385-94.

36. Dietz PM, Callaghan WM, Morrow B, et al. Population-based assessment of the risk of primary cesarean delivery due to excess prepregnancy weight among nulliparous women delivering term infants. Matern Child Health J. 2005;9(3):237-44.

37. Norman SM, Tuuli MG, Odibo AO, et al. The effects of obesity on the first stage of labor. Obstet Gynecol. 2012;120(1):130-5.

38. Zhang J, Bricker L, Wray S, et al. Poor uterine contractility in obese women. BJOG. 2007;114(3):343-8.

39. Young TK, Woodmansee B. Factors that are associated with cesarean delivery in a large private practice: The importance of prepregnancy body mass index and weight gain. Am J Obstet Gynecol. 2002;187(2):312-20.

40. Gaudet L, Ferraro ZM, Wen SW, et al. Maternal obesity and occurrence of fetal macrosomia: A systematic review and metaanalysis. Biomed Res Int. 2014;2014:640291.

41. Tanaka K, Matsushima M, Izawa T, et al Influence of maternal obesity on fetal growth at different periods of pregnancies with normal glucose tolerance. J Obstet Gynaecol Res. 2018;44(4):691-6. 
42. Boulet SL, Alexander GR, Salihu HM, et al. Macrosomic births in the United States: Determinants, outcomes, and proposed grades of risk. Am J Obstet Gynecol. 2003;188(5):1372-8.

43. Merzouk H, Meghelli-Bouchenak M, Loukidi $\mathrm{B}$, et al. Impaired serum lipids and lipoproteins in fetal macrosomia related to maternal obesity. Neonatology. 2000;77(1):17-24.
44. Ahlsson F, Diderholm B, Jonsson B, et al. Insulin resistance, a link between maternal overweight and fetal macrosomia in nondiabetic pregnancies. Horm Res Paediatr. 2010;74(4):267-74.
45. Sewell MF, Huston-Presley L, Super DM, et al. Increased neonatal fat mass, not lean body mass, is associated with maternal obesity. $\mathrm{Am} \mathrm{J}$ Obstet Gynecol. 2006;195(4):1100-3. 